\title{
Doktorsfrau und Frau Doktor: beiden sei Dank
}

Länger schon diente dem Arzte als Hilfskraft treu seine Gattin bei Tag und bei Nacht, und es galt immer als vorbildlich-standhaft, dass sie kaum Pausen noch Ferien gemacht.

Heute noch gründet auf diesem Verbunde da oder dort ganz der ärztliche Ruf, der von der Praxis im Dorf macht die Runde, sinngemäss wie auch Frau Doktor ihn schuf.

Doch man bedachte sie kaum mit dem Lobe, weil man nur würdig den Gatten befand, selbst wenn durch Buchführung, Mahlzeit, Garderobe diesem dank ihr seine Basis entstand.

Immer noch hält auch im widrigsten Falle sie fest zu ihm und bedauert es nicht, schirmt ihn klug ab von manch wortreichem Schwalle, scheidet das Heucheln vom wahren Bericht.

Zielbewusst lenkt sie den Lauf ihrer Tage, hat für die Armen ein Herz, und sie weiss um gar so manche erschütternde Klage, hilft an den Orten der Not, aber leis.

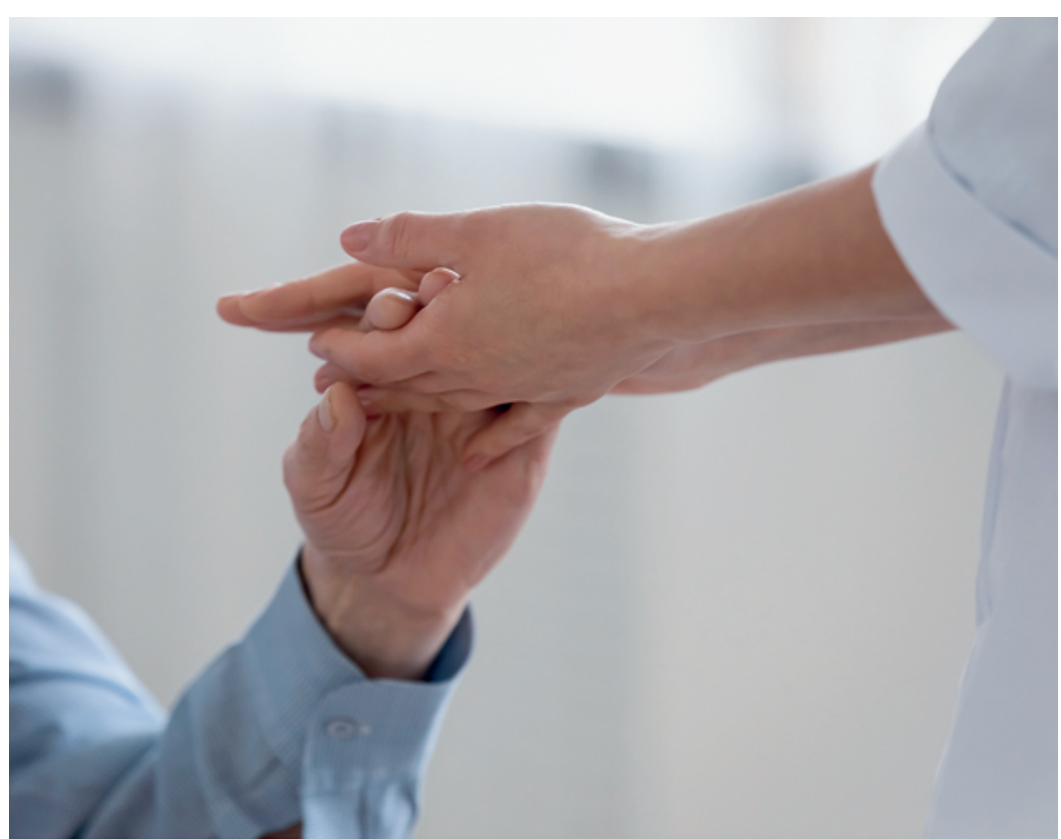

In dem Verein ist sie aktiv fürs Ganze, füllt aus ein Ehrenamt gerne mit Sinn, steht nicht zuvorderst genüsslich im Glanze, aber trägt bei zum Gemeinschaftsgewinn.

Längst hat verdient sie das Lob unseres Standes, welches ihr blieb für Jahrzehnte versagt, und es ist würdig des Ärzteverbandes, dass man, was fällig, nicht länger vertagt:

Dank ihr zu spenden, dass lang ihre Rolle hat hierzulande das Arztsein gestärkt, deshalb, so hofft man, dass annehmen wolle sie diesen Dank und es freudig vermerkt.

Langsam nun geht eine Phase zu Ende, welche den Kranken noch sehr ist genehm; viele geschickte und emsige Hände lindern und lösen das Hausarztproblem:

die, der zur Ärztin berufenen Frauen, welche - auch teilzeitig - voller Elan. Und weil es reifte, so rief das Vertrauen bald sie zur Hausärztin neu auf den Plan.

Ärztinnenhände betreuen mehr Kranke und es lebt weiter entsprechend die Kunst, und unser Stand ist drauf stolz und sagt danke, dass ihm vermehrt gilt die weibliche Gunst.

Prof. em. Dr. med. Max Stäubli, Ebmatingen

Bildnachweis

Fizkes | Dreamstime.com, Symbolbild

Zufällig passen die Verse zur Einführung des Frauenstimmrechtes vor 50 Jahren. Schon in der Bibel wurden Anmut, Klugheit und Tüchtigkeit der Frauen gepriesen: Altes Testament, Buch der Sprüche, Kapitel 31. Jener Text diente Bernhard Gurtner für «Powerfrowen» (Schweiz Ärzteztg. 2003;84(11):503) als historische Vorlage. Er hat mich zum vorliegenden Gedicht freundschaftlich ermuntert. 